Poor COWS
US edges towards
wider testing of
cattle for BSE
p766

\title{
Media attack prompts editorial backlash against MMR study
}

\section{Jim Giles, London}

A leading medical journal has taken the unusual step of distancing itself from one of its own papers and attacking its findings.

Editors at The Lancet launched a preemptive media strike on 18 February after learning that The Sunday Times was investigating undeclared conflicts of interest in a 1998 paper linking autism with the measles, mumps and rubella (MMR) vaccine. The editors went public two days before the story was due to be published, declaring that the autism paper was "flawed" and should not have been published in its original form.

The paper triggered huge public controversy in Britain over the safety of the MMR vaccine. In it, lead author Andrew Wakefield, a gastroenterologist then at the Royal Free Hospital in London, described a group of eight children with behavioural problems and noted that their parents reported problems beginning within two weeks of the children receiving MMR jabs (A. Wakefield et al. The Lancet351, 637-641; 1998).

At a press conference before publication, Wakefield said that the three vaccines should not be administered in combination until the issue had been resolved. Subsequent epidemiological studies failed to find a link with autism and led many of Wakefield's co-authors to distance themselves from his claims. But this did not stop the paper and Wakefield's continuing criticism of the vaccine from having a dramatic effect.

Conflicting, high-profile television and newspaper reports about the safety of the triple vaccine confused parents. Prime Minister Tony Blair, who urged parents to have their children vaccinated, came under pressure in parliament to reveal whether his three-year-old son had received the jab. National take-up of the MMR jab dropped from around $90 \%$ in 1998 to its current level of less than $80 \%$.

But unknown to The Lancet, Wakefield had been asked to conduct a separate study into whether parents whose children had allegedly been harmed could sue manufacturers of the MMR vaccine. The Legal Aid Board, which then administered government funding for such claims, paid Wake-

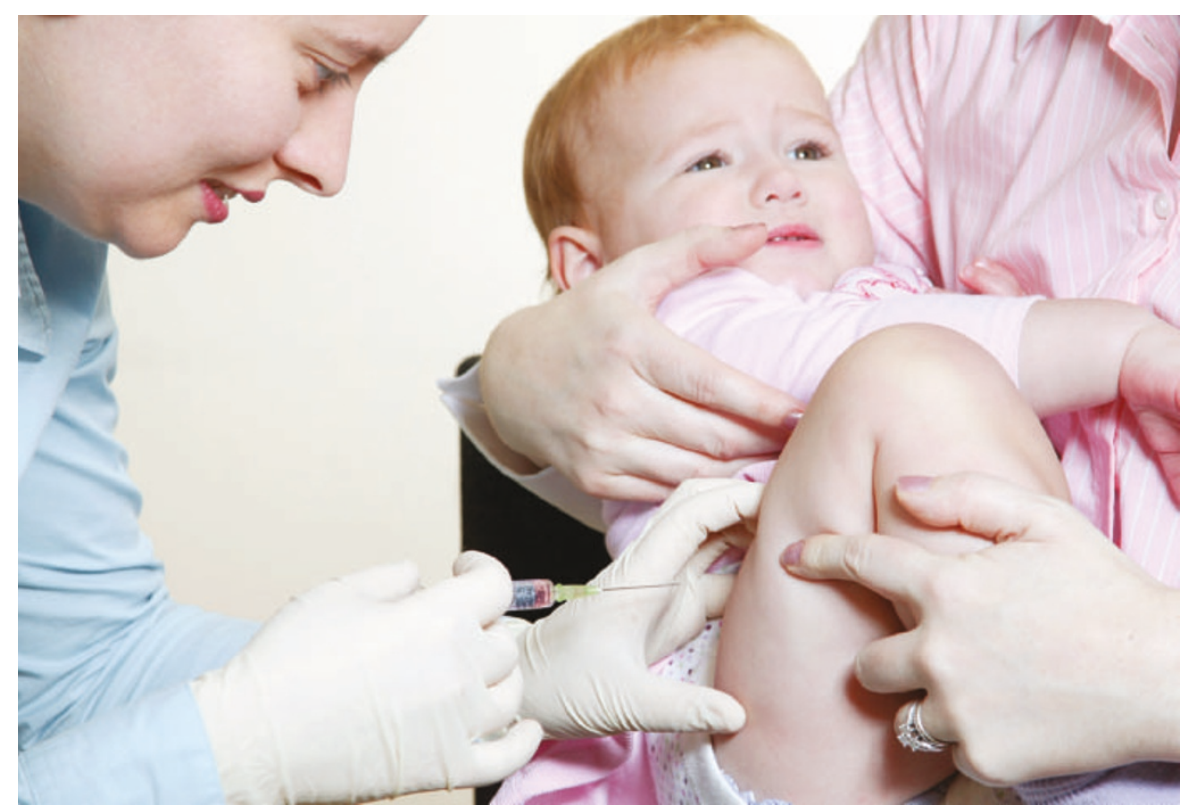

Tough call: UK parents panicked following claims that the MMR vaccine might cause autism.

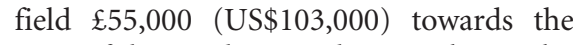
costs of that study, according to The Sunday Times. The newspaper said that at least four children took part in both studies.

In last week's statement, editors at the journal said Wakefield's failure to disclose the existence of the legal-aid study was a clear breach of its conflict-of-interest policy, which in 1998 stated that authors should reveal anything "that would embarrass you if it were to emerge after publication and you had not declared it".

Astrid James, the journal's deputy editor, says that the actual data in the paper are not being questioned, but that reviewers and editors would have viewed Wakefield's interpretation differently had they known the source of the funding. "The link with MMR is flawed," says James. "We would have asked authors to change that section." The journal will publish a commentary on the paper, together with statements from the original authors, in the next few weeks.

The Lancet's verdict is in line with mainstream opinion on the Wakefield paper, but the journal's reaction has surprised some people in scientific publishing. Richard
Smith, editor of the British Medical Journal $(B M J)$, agrees that the paper is flawed on scientific grounds, but questions whether a declaration of conflict of interest would have affected the decision to publish.

Smith says that the $B M J$ regularly publishes papers by authors who have been paid to act as expert witnesses in court cases. The journal also accepts papers from researchers working for pharmaceutical companies. "Drug company employees have more extreme conflicts of interest," Smith says, adding that journals usually deal with these by disclosing them — not by asking authors to change their paper.

Wakefield has left the Royal Free and is now director of an autism research centre in Florida. He accepts that he was funded by the Legal Aid Board, but says that the results of the Lancet paper did not affect the possibility of a case being brought, and his funding was therefore irrelevant.

He could now face an investigation by the General Medical Council, the body that regulates doctors - a prospect which Wakefield said in a statement he welcomed as an opportunity to clear his name. 